\title{
OXIDATION MECHANISMS IN RELATION TO HIGH TEMPERATURE FATIGUE CRACK GROWTH PROPERTIES OF ALLOY 718
}

\author{
E. Andrieu, G. Hochstetter, R. Molins and A. Pineau \\ Ecole Nationale Supérieure des Mines de Paris \\ Centre des Matériaux P.M. Fourt \\ BP. 87, 91003 Evry Cedex 03 \\ URA CNRS 866
}

\begin{abstract}
High temperature fatigue crack growth rate (FCGR) tests were performed at elevated temperature $\left(-650^{\circ} \mathrm{C}\right)$ under different oxygen partial pressures, $\mathrm{PO}_{2}$, ranging from $10^{-8}$ mbar to 0.2 bar on one heat of Alloy 718. A sharp transition in the FCGR was observed to take place for a pressure close to $10^{-3} \mathrm{mbar}$. The FCGR decreases by almost three orders of magnitude when $\mathrm{PO}_{2}$ decreases from about $10^{-1}$ mbar down to $10^{-3} \mathrm{mbar}$ and when the material is tested at $650^{\circ} \mathrm{C}$ under $\Delta \mathrm{K} \sim 20 \mathrm{MPa} \sqrt{\mathrm{m}}$. The effect of loading frequency as well as the influence of Kmax on the transition pressure were also investigated. No influence of the mechanical loading conditions were found on the transition pressure provided that the mechanical conditions are in the range corresponding to an oxygen-assisted crack growth mechanism. It is shown that in this material the transition pressure is related to a particular oxidation behavior. Above the transition pressure the first oxide to be formed is a (Ni, $\mathrm{Fe}) \mathrm{O}$ oxide, while below the transition, $\mathrm{Cr}_{2} \mathrm{O}_{3}$ type oxide is formed preferentially. These conclusions are drawn through TEM observations and chemical analysis of the oxides formed on the surface of the specimens tested under specific conditions. These results are used to discuss the strong environmental effect observed in Alloy 718.
\end{abstract}

\section{Introduction}

Alloy 718 is a precipitation strengthened nickel-base superalloy widely used in aerospace and nuclear applications under static as well as cyclic conditions at both high $\left(650^{\circ} \mathrm{C}\right)$ and medium temperature ranges in agressive environment. Extensive evidence exists in the literature showing that the fatigue as well as the creep crack growth rates under air environment are the results of an agressive effect of oxygen,.(see e.g (1)).The effects of mechanical, microstructural and environment variables on the crack propagation resistance of Alloy 718 have been widely studied.A recent review has been published on this topic. $(2,3)$.

It is worth mentionning that in the most detrimental conditions, i.e creep crack growth under air, the crack growth rates can reach values as large as a mm per hour while under vacuum and under the same loading conditions the crack propagates a thousand times slower. It seems

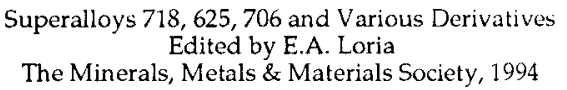


therefore obvious that increasing the crack propagation resistance of Alloy 718 would result in enlarging the application field of this alloy and making easier prediction of crack growth rate behavior under typical service conditions. However, the enhancement of cracking resistance by microstructural and chemical composition modifications suppose that the mechanisms by which embrittlement occurs are well understood.The main objective of the present study is to contribute to a better understanding of the oxidation-assisted crack growth phenomenon encountered in most of the Ni-based superalloys. The approach chosen in the present study is two fold :

- Since high crack growth rates can be found during mechanical testing, the study is focussed on early stages of oxidation process. The oxygen partial pressure $\left(\mathrm{PO}_{2}\right)$ is used as the environmental variable so that fatigue crack growth rate measurements have been performed under constant $\triangle \mathrm{K}$ and various $\mathrm{PO}_{2}$ at $650^{\circ} \mathrm{C}$.

- The second part of this study is devoted to a detailed analysis of the oxides formed on the fracture surface by means of transmission electron microscopy (TEM). Cross sectional thin foils have been observed and analysed in order to characterise the oxidation behavior of the alloy.

\section{$\underline{\text { Material and experimental procedures }}$}

The chemical composition of the alloy investigated in this study is given in table 1 .

Alloy 718 was received as a wrought bar of $200 \mathrm{~mm}$ diameter which was given a solution heat treatment at $1050^{\circ} \mathrm{C}$ for 1 hour. A conventional heat treatment was given : $955^{\circ} \mathrm{C}$ during 1 hour, then air cooled down to $720^{\circ} \mathrm{C}$ for 8 hours and air cooled at $50^{\circ} \mathrm{C} /$ hour down to $620^{\circ} \mathrm{C}$ and maintained 8 hours. The resulting microstructure is shown in figure 1.The average grain size has been measured $(\varnothing=150 \mu \mathrm{m})$; it corresponds to a large grain material with a very small amount of intergranular $\delta$ phase precipitates. The two strengthening phases $\gamma^{\prime}$ and $\gamma^{\prime \prime}$ are homogeneously distributed in the matrix.The volume fraction of precipitates is about $15 \%$. The tensile properties of this material are reported in table 2 .

Table 1 - Chemical composition (wt\%)

\begin{tabular}{|c|c|c|c|c|c|c|c|c|c|c|c|c}
\hline $\mathbf{C}$ & $\mathbf{C r}$ & $\mathbf{M} \mathbf{o}$ & $\mathbf{T} \mathbf{i}$ & $\mathbf{A ~} \mathbf{l}$ & $\mathbf{N b + T a}$ & $\mathbf{F e}$ & $\mathbf{S ~ i}$ & $\mathbf{C o}$ & $\mathbf{M n}$ & $\mathbf{P}$ & $\mathbf{S}$ & $\mathbf{B}$ \\
\hline 0,035 & 18.25 & 3.06 & 1.02 & 0.54 & 5.27 & 19.00 & 0.09 & 0.25 & 0.13 & 0.009 & 0.0015 & 0.006 \\
\hline
\end{tabular}

Table 2 : Tensile properties.

\begin{tabular}{cccc}
\hline $\begin{array}{c}\text { Temperature } \\
\left({ }^{\circ} \mathbf{C}\right)\end{array}$ & $\begin{array}{c}\mathbf{R}_{\mathbf{0 , 2}} \\
(\mathbf{M P a})\end{array}$ & $\begin{array}{c}\mathbf{R}_{\mathbf{m}} \\
(\mathbf{M P a})\end{array}$ & $\begin{array}{c}\mathbf{A} \\
(\boldsymbol{\%})\end{array}$ \\
\hline 25 & 1145 & 1290 & 24 \\
650 & 885 & 960 & $\mathbf{1 7}$ \\
\hline
\end{tabular}


For the fatigue tests, $C T 20$ specimens $(B=10 \mathrm{~mm}, W=40 \mathrm{~mm})$ were used. The specimens were fatigue precracked at room temperature with a loading frequency of $50 \mathrm{~Hz}$ up to $\mathrm{a} / \mathrm{w}=0.35$ and then precracked at high temperature with a(10s-300s hold time-10s)cycle till a/w $=0.40$ was reached.The latter part of the precracking was used in order to obtain an intergranular precrack. The maximum a/w value reached during the experiments was equal to 0.7 .The crack length was measured by using the potential drop technique.The fatigue testing frame was equipped with a high vacuum chamber. Pressures were measured from 1 bar to 10 mbar with a manometer with a Pirani gauge for pressures ranging between $10^{-3}$ mbar and $5 \mathrm{mbar}$ and a Bayard-Alpert gauge for lower pressures.A technique,similar to that used by other investigators (4), was developped to prepare cross sectional thin foils located close to the fracture surfaces. TEM investigations were carried out with a $300 \mathrm{KV}$ microscope equipped with an X.Ray (EDS) spectrometer.The oxides and microstructural variations were identified by using electron diffraction techniques and elemental concentration linescans with a few nanometers probe size.

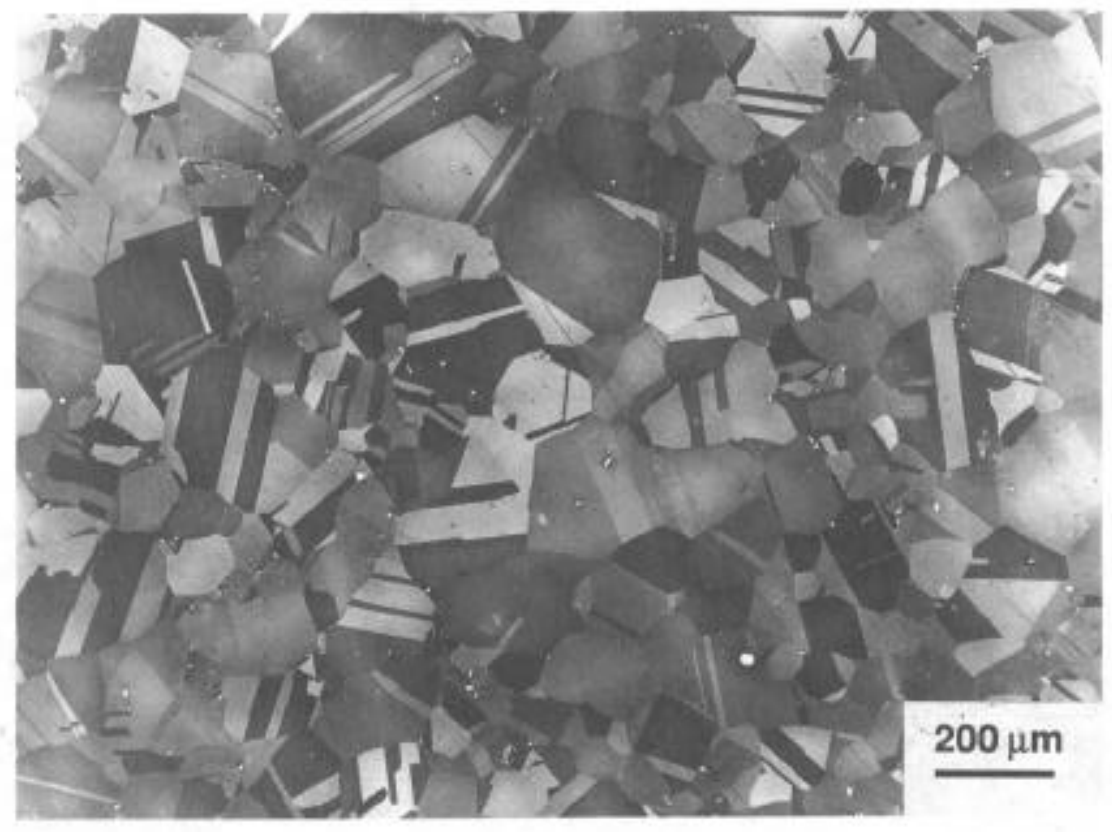

Figure 1 : Optical micrograph showing the microstructure of the alloy studied. 


\section{$\underline{\text { Results and discussion }}$}

The results presented in this section are part of a more extensive study on creep and fatigue crack growth properties of Alloy 718, see e.g(5-8).As far as environmental effects are concerned, the results included in this section are only those in wich environment plays an important role. Consequently, the shape and the frequencies of the cycles are chosen so that the coupling between oxidation process and crack tip deformation mode lead to a significant embrittlement of the grain boundaries.

\section{Effect of oxygen partial pressure on fatigue crack growth rate}

Fatigue tests were carried out at $650^{\circ} \mathrm{C}$, under constant $\triangle \mathrm{K}$ and at different $\mathrm{PO}_{2}$. A trapezoidal cycle shape (10s-300s hold time-10s) was chosen with a load ration, $R=0.1$. Each measurement of the crack growth rate at a given oxygen partial pressure has been performed after a crack propagation of at least $1 \mathrm{~mm}$. The results of these tests are reported in figure $2 . \mathrm{K}$ values of $20 \mathrm{MPa} \mathrm{m}{ }^{1 / 2}$ and $28 \mathrm{MPa} \cdot \mathrm{m}^{1 / 2}$ have been explored.It is worth noting that an abrupt transition in fatigue crack growth rate appears when the oxygen partial pressure is close to $10^{-3}$ mbar.Moreover, it is important to notice that for a sligth increase of the pressure from $10^{-3}$ to $10^{-2}$ mbar the crack growth rate is multiplied by 2 or 3 orders of magnitude. The first clear demonstration of the effect of $\mathrm{PO}_{2}$ on the fatigue crack growth rate has been reported by Smith et al (9) in the case of 316 stainless steel alloy. Similar effects of $\mathrm{PO}_{2}$ have been observed in other materials, see e.g(10-14). An adsorption model was then proposed by Achter (15) to explain the observed transitions in terms of impingement rate of oxygen molecules on the freshly exposed metals atoms. This adsorption model predicts that the crack growth rate should increase with partial oxygen pressure until a critical pressure at which the rate of surface coverage equals the rate of surface formation.

Several observations reported in the present study cannot be explained by this model. The essential observations are the following :

- the crack propagation mode changes from transgranular when $\mathrm{PO}_{2}$ is lower than $10^{-3}$ mbar to fully intergranular when $\mathrm{PO}_{2}$ is higher than $10^{-3}$ mbar.

- the crack growth rate remains insensitive to oxygen partial pressure in the range $\left(10^{-9} \mathrm{mbar}-\right.$ $10^{-3}$ mbar).

Another mechanism has therefore to be found to explain the observed transition. Moreover,under similar experimental conditions another transition was found on a rather different Ni-base superalloy which is N18 Alloy (8).For comparison this transition curve is presented in figure 3. N18 alloy is a powder metallurgy Ni base superalloy containing much more strengthening elements as compared to Alloy 718 . In thi material the volume fraction of $\gamma^{\prime}$ reaches $45 \%$ and chromium content of the matrix is close to $25 \%$ (weight $\%$ ). The striking features of the curve shown in figure 3 is that the value of the transition pressure is the same as that found for Alloy 718. Despite of the difference in the amplitude of the transition which is much smaller in the case of N18 Alloy, it seems that oxygen embrittlement phenomena is similar for both materials. 


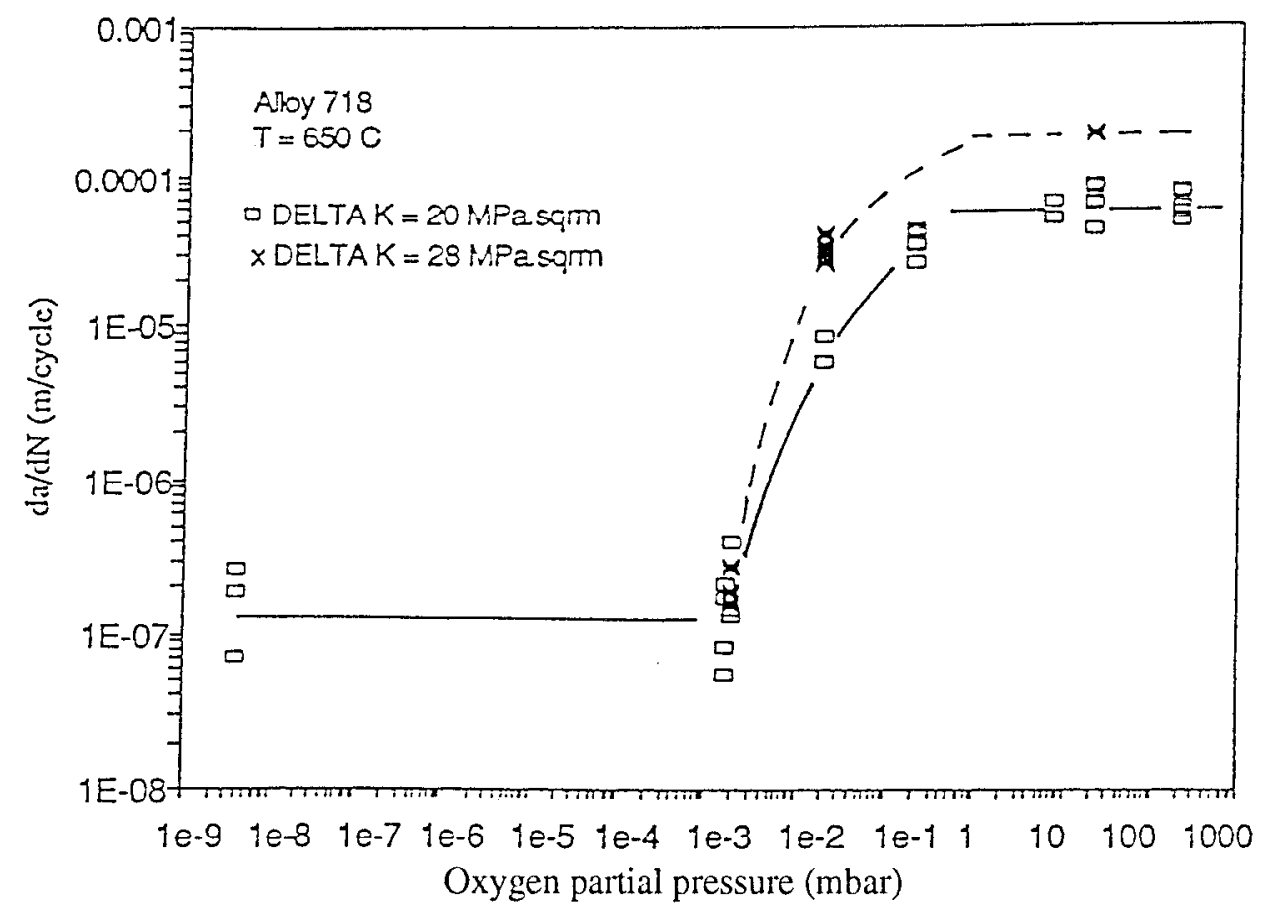

Figure 2 : Fatigue crack growth rate as function of the oxygen partial pressure under constant $\Delta \mathrm{K}(20$ and $28 \mathrm{MPa} \sqrt{\mathrm{m}})$ at $650^{\circ} \mathrm{C}$ in Alloy 718 .

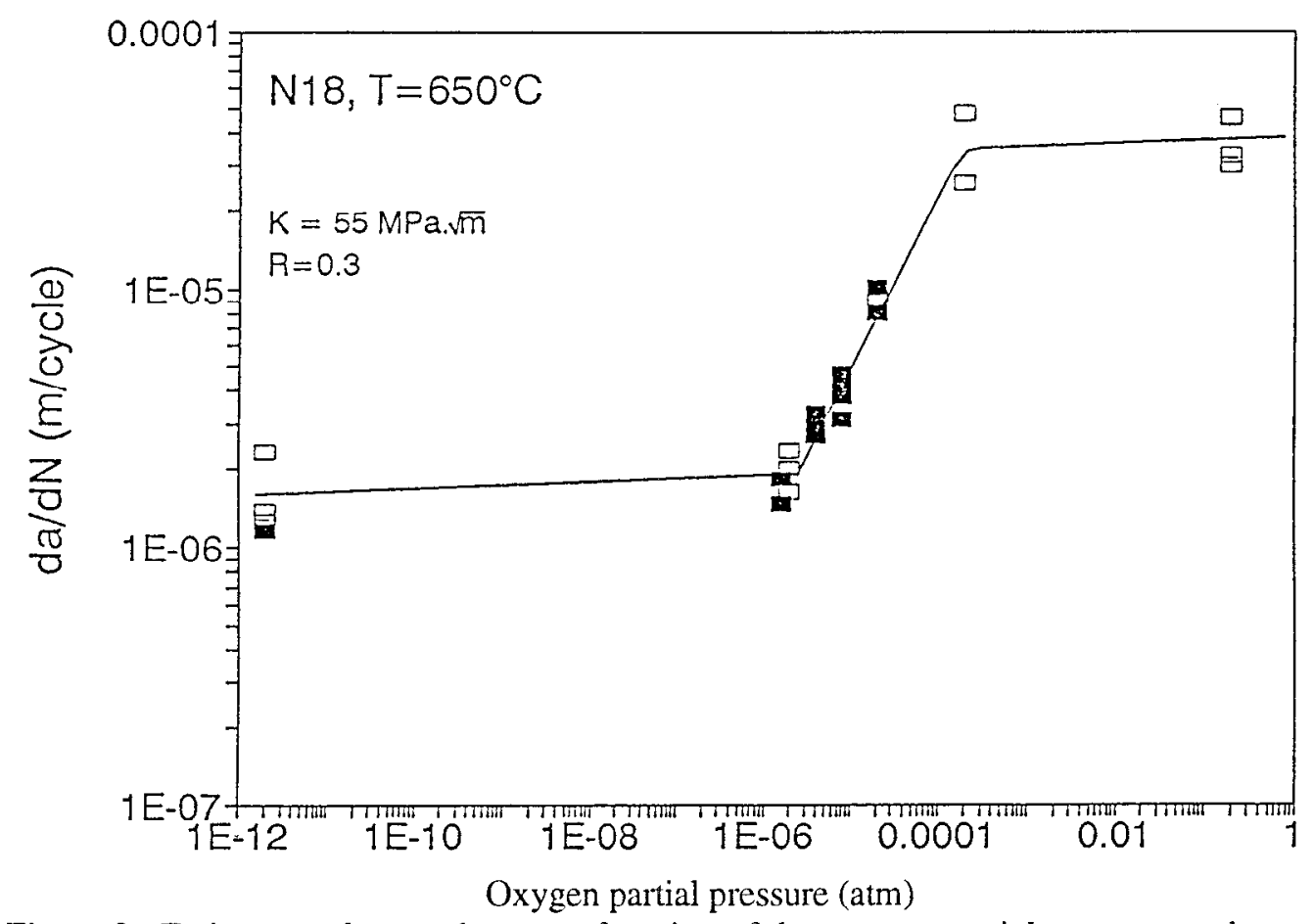

Figure 3 : Fatigue crack growth rate as function of the oxygen partial pressure under constant $\Delta \mathrm{K}(\mathrm{Kmax}=55 \mathrm{MPa} \sqrt{\mathrm{m}})$ in N18 Alloy. 
Another interesting observation that can be made on figure 2 is related to the shape of the curve. Three domains can be defined : the first one corresponds to pressures lower than the transition pressure. In this part of the curve the crack growth rate is fully controlled by a mechanical damaging process. The second one is located in the pressure range inside of which the crack growth rate increases with the pressure. This means that the kinetic of the oxidaton damaging process controls the crack propagation. This domain is of major interest to investigate the kinetic of embrittlement by oxygen. In the last part of the curve,the crack growth rate doesn't vary very much with pressure. At this stage, the local mechanical behaviour at the crack tip is the rate controlling parameter.

From this description a question arises. How does the shape of this curve vary with mechanical testing conditions? The next section is devoted to this specific point.

\section{Effect of loading frequency}

Two other testing frequencies were chosen. Triangular cycles with frequencies equal to $510^{-2} \mathrm{~Hz}$ and $510^{-1} \mathrm{~Hz}$ were used. The results of these further tests are given in Fig.4. These results show that the transition in crack growth rate takes place at the same oxygen partial pressure. This means that the oxygen damaging process is independent of the applied loading conditions, as shown earlier (Fig.2).

Furthermore, at a frequency of $510^{-2} \mathrm{~Hz}$ a plateau is reached similarly to the situation observed with 10-300-10 cycle. It is worth noting that the crack growth rate corresponding to these two cycles are almost the same provided that they are expressed on a lime basis. This strongly suggests that under air environment the crack growth rate behaviour is only time dependent and moreover $\mathrm{K}_{\max }$ dependent.

Further tests carried out on N18 Alloy showed that in this domain of oxidation assisted growth the kinetic of crack propagation was not dependent on $R$ ratio but unequally on $K_{\max }$ (16). $A$ similar behaviour was noticed in an extensive study dealing with Alloy $718(2,3)$.

Finally the frequency of $510^{-1} \mathrm{~Hz}$ corresponds to the transition domain in fracture mode between intergranular fracture at lower frequency and transgranular fracture at higher frequency. This produccs under atmospheric pressure a mixed mode of fracture. This might explain why a plateau in crack growth rate is not reached. 


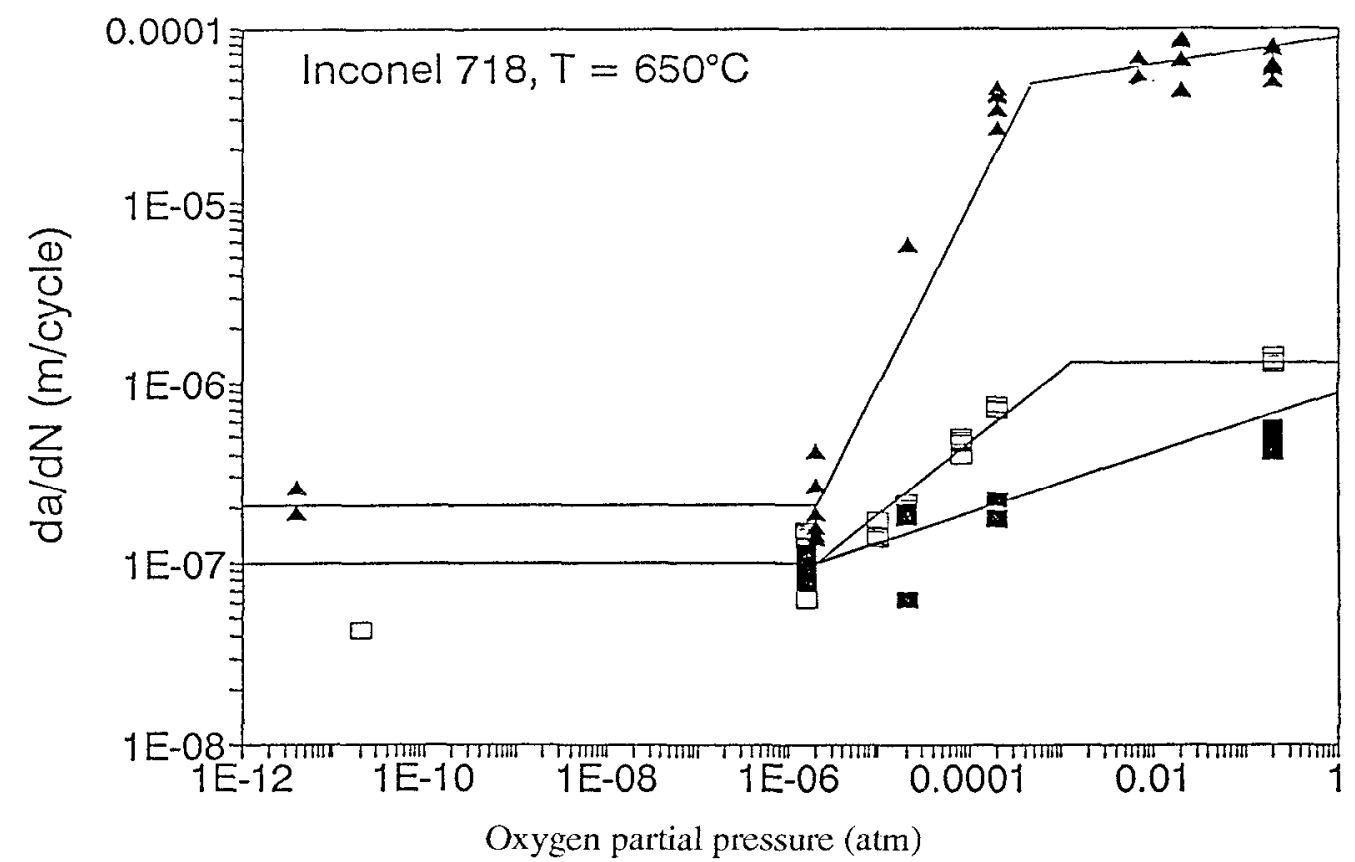

Figure 4 : Loading frequency effect on the transition curve in Alloy 718 at $650^{\circ} \mathrm{C}$.

$$
\begin{aligned}
& \Delta(10 \mathrm{~s}-300 \mathrm{~s}-10 \mathrm{~s})-\Delta \mathrm{K}=20 \mathrm{MPa} \sqrt{\mathrm{m}} \mathrm{R}=0.1 \\
& \square(10 \mathrm{~s}-10 \mathrm{~s})-\Delta \mathrm{K}=18 \mathrm{MPa} \sqrt{\mathrm{m}} \mathrm{R}=0.1 \\
& \mathbf{a}-1 \mathrm{~s})-\Delta \mathrm{K}=18 \mathrm{MPa} \sqrt{\mathrm{m}} \mathrm{R}=0.1
\end{aligned}
$$

Oxidation of Alloy 718 . In a previous study devoted to this topic, a selective oxidation process was identified. The results of A.E.S elemental profiles obtained on Alloy 718 specimens oxidised at $650^{\circ} \mathrm{C}$ under different oxygen partial pressures are given in figure 5. It is shown on this series of profiles that under pressures lower than $10^{-4}$ Torr $(1 \mathrm{mbar}=0.75 \mathrm{Torr})$, the first oxide to be formed is chromium oxide. On the contrary, when the samples are oxidised under pressures higher than $10^{-2}$ Torr the first oxide to appear is a Nickel-base oxide. However, these profiles have been obtained on mechanically polished specimens so that the question of their relevancy to the case of an oxidised fracture surface is raised. In order to answer to this point, cross sectional thin foils were made on fracture surfaces and subsequently observed and analysed. For comparison two TEM micrographs are shown in figures 6 and 7. They refer to Alloy 718 and N18 Alloy which exhibits a transition in the fatigue crack growth rate for similar oxygen partial pressure. The CT specimens used to extract the thin foils were fatigue cracked under air laboratory at $650^{\circ} \mathrm{C}$ so that the fracture surface was intergranular. The observation of the two micrographs reveals that the oxide scale consists of two separated layers. The grain size of the outer layer is larger than the one of the inner layer. The important thickness of these oxides layers results from long time exposures (several days). 

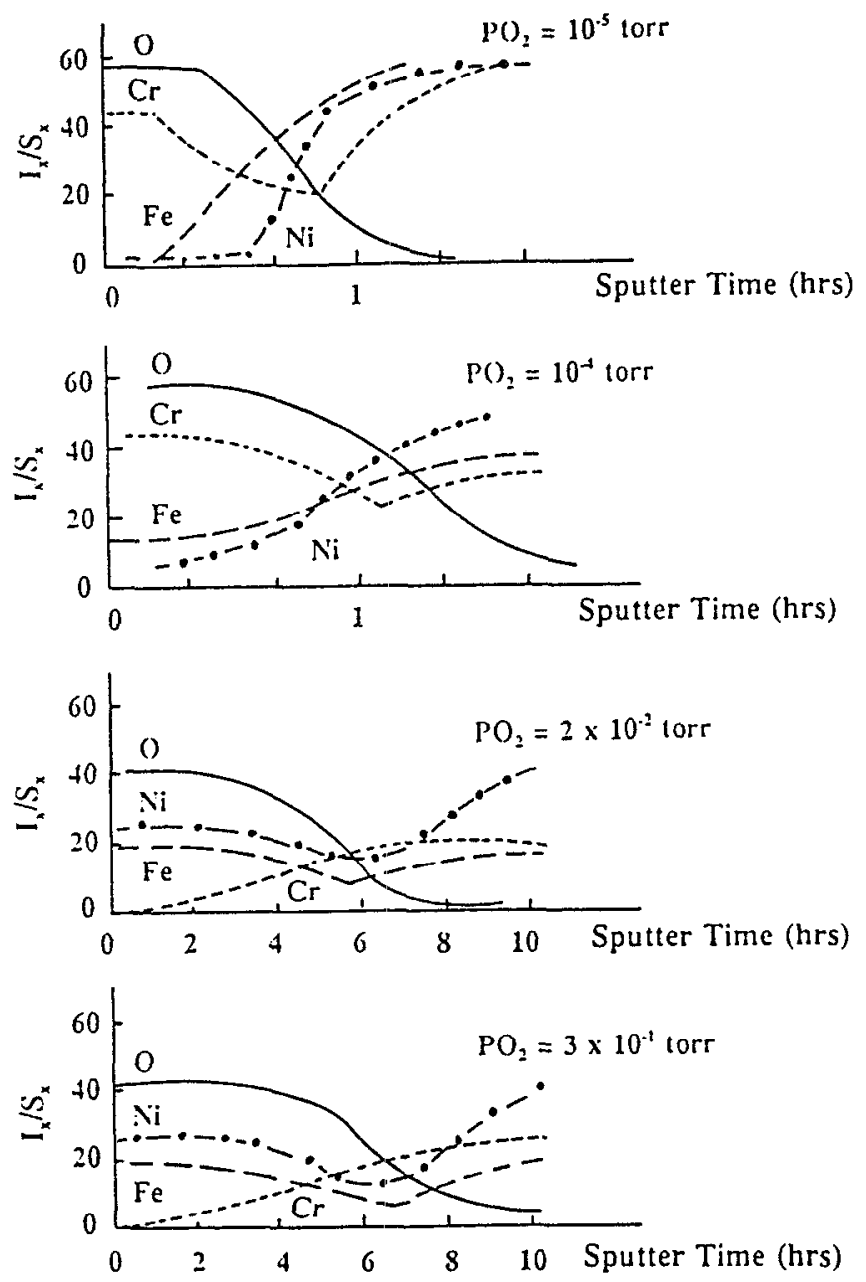

Figure 5 : Effect of oxygen partial pressure on A.E.S. elemental profiles of oxidized samples, $\mathrm{t}_{\mathrm{ox}}=8 \mathrm{mn}, \mathrm{T}=650^{\circ} \mathrm{C}(\operatorname{ref} 7)$. 

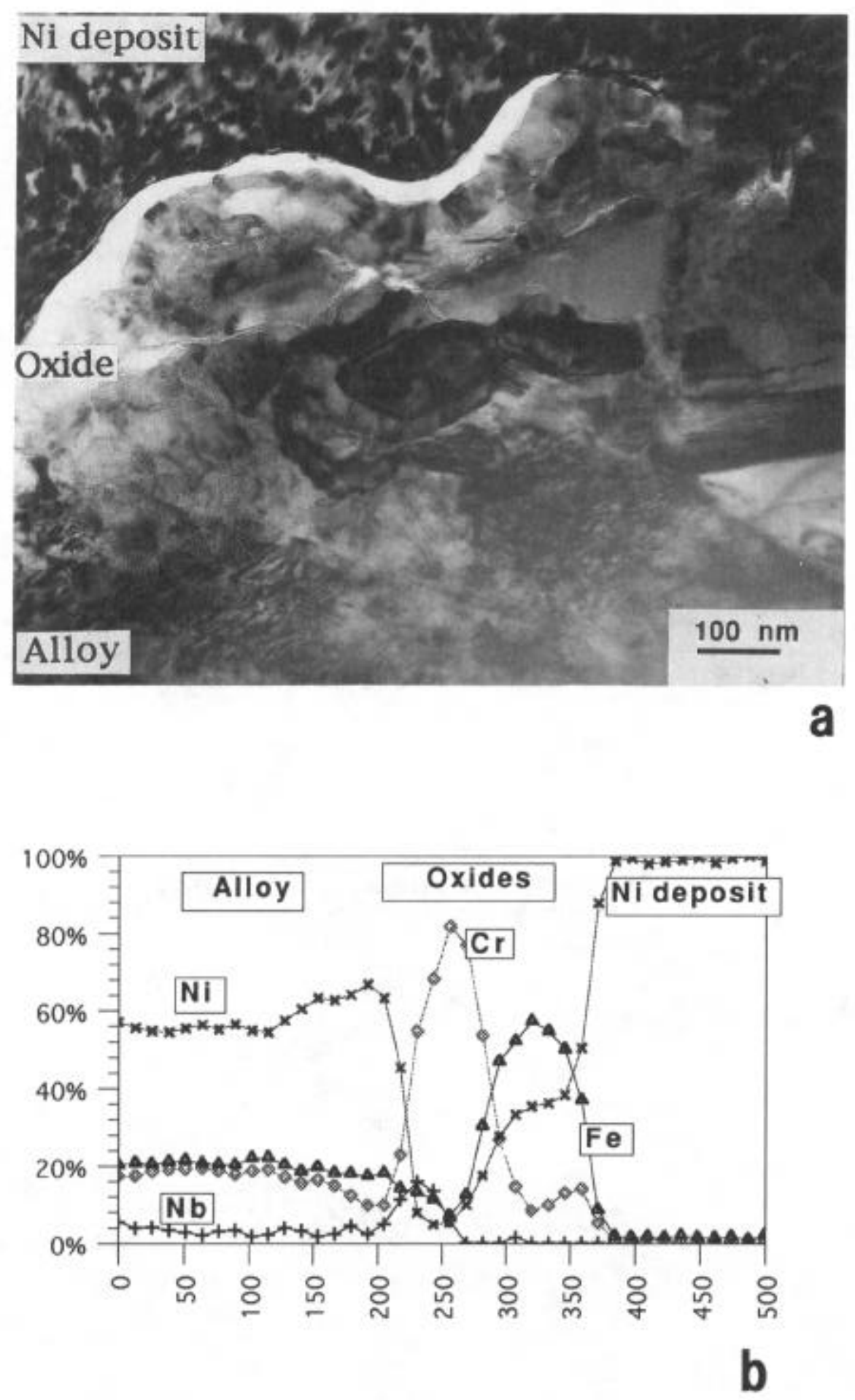

Figure 6: Alloy 718, Oxidation of an intergranular fracture surface

a) TEM observation

b) Elemental linescan across the alloy/oxide interface. 


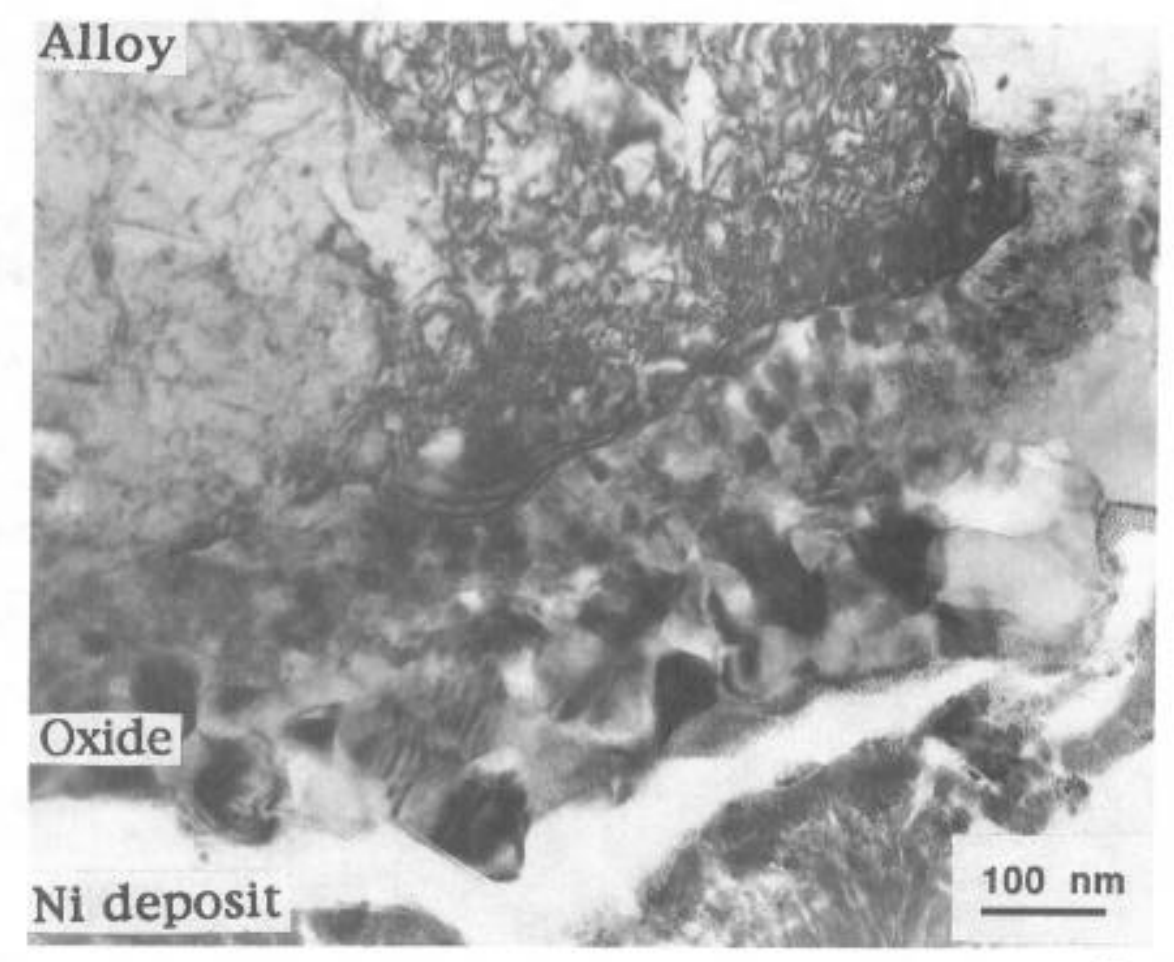

a

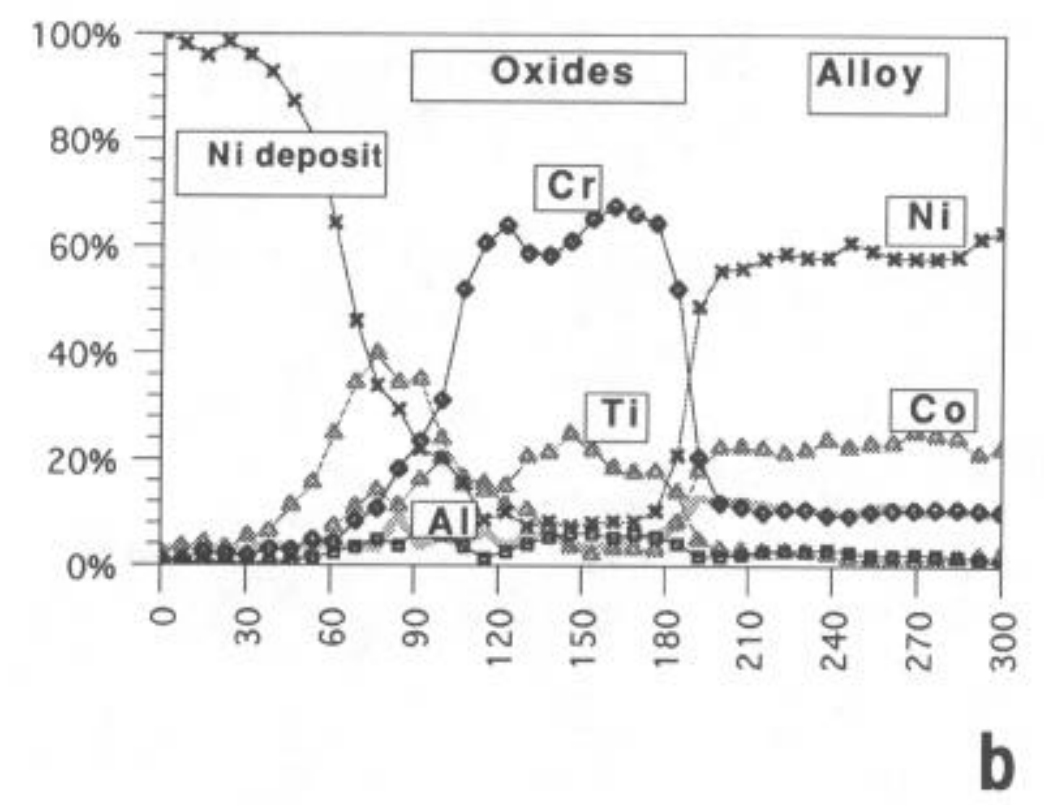

Figure $7:$ N18: Oxidation of an intergranular fracture surface.

a) TEM observation

b) Element linescan across the alloy/oxide interface. 
Figures 6 and 7 show associated linescan taken on transverse sections of intergranular fracture surfaces. A duplex oxide scale is observed again. The outer scale was identified as $\mathrm{Ni}$ baseoxide, Iron rich for Alloy 718 and Cobalt rich for N18. This means that in the oxidation assisted crack growth domain the first oxide to appear is a Nickel-base oxide. Later on, a protective fine grain subscale is formed which was identified as a chromia scale for both alloys. This step of the oxidation process corresponds to the passivation of the alloy. The composition of the intermediate scale for Alloy 718 varies form $\mathrm{Cr}_{2} \mathrm{O}_{3}$ near the $\mathrm{NiO}$ interface to $\mathrm{Cr}(\mathrm{Nb}$, Ti) $\mathrm{O}_{4}$ at the metal/oxide interface It is interesting to note that there is no difference between the oxidation behaviour of mechanically polished surfaces and fatigue deformed surfaces, at least under the mechanical loading conditions which were investigated.

One of the consequences of the oxidation of Alloy 718 is shown in figure 8 . The dark field imaging shows the disappearing of the hardening precipitates beneath the oxide. This can be explained by the depletion of chromium in the matrix, causing the dissolution of $\mathrm{Ni}_{3}(\mathrm{Ti}, \mathrm{Al})$ and $\mathrm{Ni}_{3} \mathrm{Nb}$. These chemical changes in the bulk near the oxidised surface lead to a local mechanical softening. Consequently, the mechanical behaviour of this oxidation affected zone is modified.

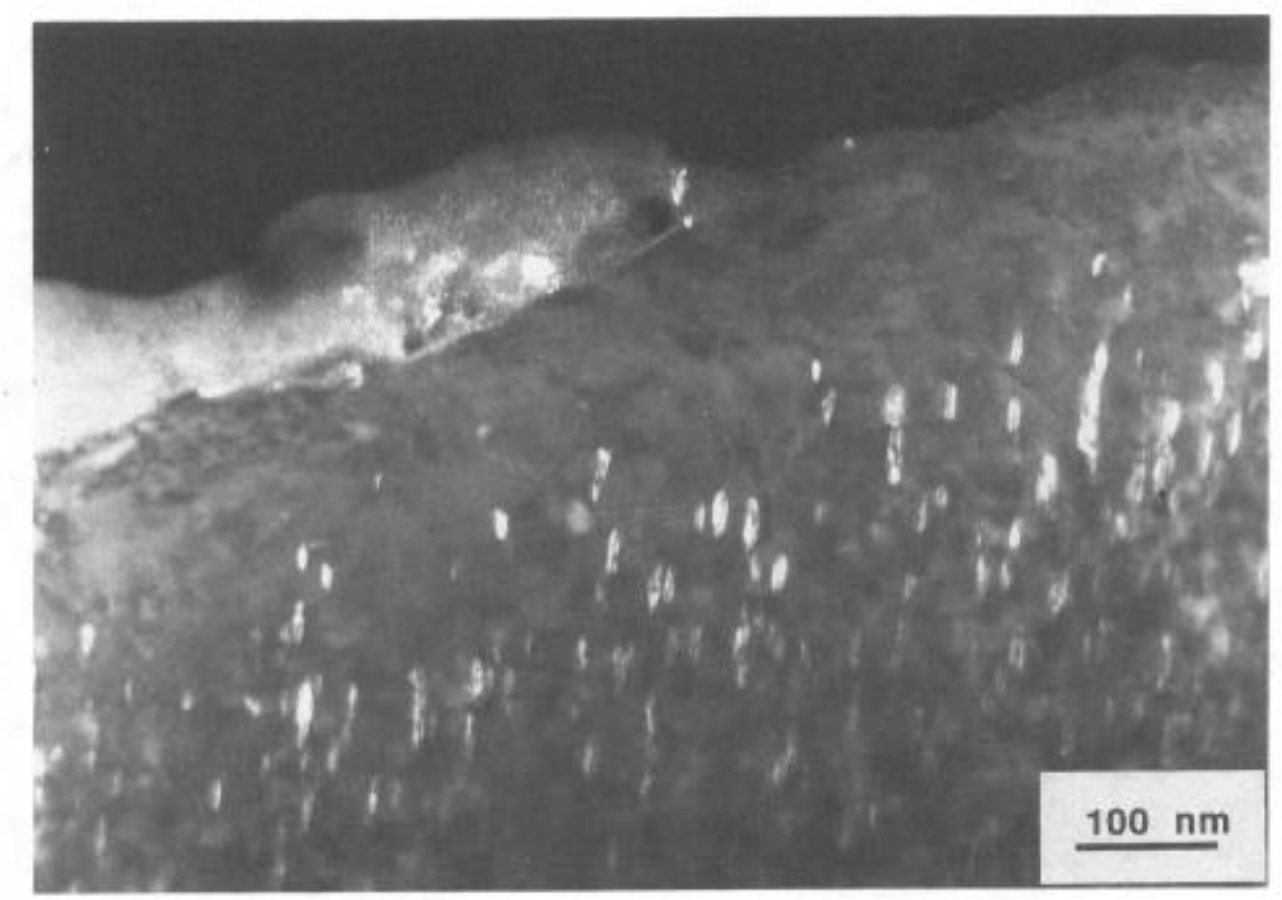

Figure 8: Alloy 718. Dark field micrograph showing, the dissolution of $\gamma^{\prime \prime}$ precipitates close to the oxide/metal interface. 
Finally, the agreement between the transition pressure determined during the first part of this study and that presented in figure 5 leads to define as a prerequisite to embrittlement the formation of a Ni-base oxide. The mechanism by which grain boundaries are embrittled is not yet clear. A short distance diffusion of oxygen in the grain boundaries during the early stage of the crack tip oxidation would explain the embrittlement and would agree with the work of Bricknell et al (17-18). In any case, the embrittlement is associated to the growth of NiO oxide. Nevertheless, the deformation mode of alloy 718 plays also a fondamental role in the intergranular crack propagation. Measurements of the plastic zone sizes as well as slip traces spacing were made in the plane strain zone of CT specimens of Alloy 718 (19). It was shown that when intergranular fracture takes place, slip traces are heterogeneously distributed even for high $\Delta \mathrm{K}$ values. Thus deformation localization appears as an essential parameter in this problem.

\section{Conclusions}

The oxidation mechanisms of Alloy 718 in relation with fatigue crack growth properties were studied. It is shown that at $650^{\circ} \mathrm{C}$, by varying the oxygen partial pressure in constant $\Delta \mathrm{K}$ fatigue loading conditions, a sharp transient in the FCGR is found for Alloy 718 in the range of $10^{-2} \mathrm{mbar}$.

From the transition curve morphology,three domains can be defined :

- A low pressure domain ( $\mathrm{P}<10^{-2}$ mbar) inside of which the FCGR is independent of the oxygen pressure i.e the crack growth rate is controlled by the mechanical parameters. In this testing conditions, a selective oxidation of chromium has been identified. Furthermore, the fracture path is transgranular.

- A intermediate domain ( $P>10-2$ mbar) whose extent depends on mechanical variables, in which the FCGR increases with the oxygen pressure. In this part of the curve, the crack growth rate is fully controlled by the oxidation kinetic which corresponds to a Nickel-oxide scale growth. In this case the crack propagates under an intergranular mode.

- At high pressure and low frequency the FCGR reaches a saturation regime and becomes independent of the oxygen pressure. The limiting factor in the crack growth process is the local mechanical response of the material. In this crack propagation regime the crack growth rate is high and the fracture made intergranular.

It is worth mentionning that the transition pressure value doesn't depend neither on crack growth rate nor on the mechanical testing conditions, at least for the values which were investigated.

It is suggested that as long as environmental effects are concerned, the formation during the early stage of oxidation of a Nickel-oxide instead of Chromia as well as deformation localization in some intense slip bands are responsible of the dramatic environmental effect encountered in this alloy.

\section{Acknowledgements}

Financial support of DRET and SNECMA compagny is greatly acknowledged. Special thanks to $\mathrm{Mr} \mathrm{M}$. Rousselot for the technical assistance. 


\section{$\underline{\text { References }}$}

1. A. Pineau, Elevated Temperature Creep-Fatigue Cracking in Relation to Oxidation Effects. "Environment Induced Cracking of Metals", Ed. R.P. Gangloff and M.B. IVES. (Nace 10, Oct. 2-7, 1988), .111-122.

2. H. Ghonem, T. Nicholas and A. Pineau, Fatigue Fract. Eng. Mater. Struct., vol.16, n ${ }^{\circ}$, $1993,565-576$.

3. H. Ghonem, T. Nicholas and A. Pineau, Fatigue Fract. Eng. Mater. Struct. vol.16, ${ }^{\circ}{ }^{6}$, 1993, 577-590.

4. S.B. Newcomb, C.B. Boothroyd and V.M. Stobbs, J. Microscopy, 140, 1985, 195.

5. J.P. Pédron and A. Pineau. Mat. Sci. Eng., Vol. 56, 1982, .143-156.

6. A. Diboine and A. Pineau, Fatigue Fract. Eng. Mat. Struct., vol.10, 1987, .141-151.

7. E. Andrieu, R. Molins, H. Ghonem and A. Pineau, Mat. Sci. Eng., A154, 1992, .21-28.

8. E. Andrieu, G. Hochstetter, R. Molins and A. Pineau, Corrosion - Déformation

Interactions, Ed T. Magnin and J.M. Gras, Fontainebleau 1992, 461-475.

9. H.H. Smith, P. Shahinian and M.R. Achter, Trans. TMS. AIME, vol.245, 1969, 947-953.

10. H.H. Smith and P. Shahinian, Met Trans., Vol. 1, 1970, .2007.

11. M.R. Achter, G. J. Danek, Jr., and H.H. Smith. Trans. of Met. Soc. of AIME, vol.227, Dec. $1963, .1297$.

12. R.L. Stegman and P. Shahinian, Fatigue at High Temperature, (ASTM STP459, ASTM, 1969), 42-58.

13. H.H. Smith and P. Shahinian. Journ. of Inst of Met., 1971, vol.99, .243.

14. T. Ericsson, Canadian Met. Q., vol.18, 1979, .177-195.

15. M.R. Achter, Scripta Met., vol.2, 1968, 525.

16. G. Hochstetter et al., Evolutions Microstructurales des Superalliages base-Nickel lors de Cycles Thermiques, (Séminaire SNECMA 22 Sept.1993).

17. D.A. Woodford and R. H. Bricknell, Scripta Met., Vol.23, 1989.

18. R.H. Bricknell and D.A. Woodford, Met. Trans., 12A, 1981, 425.

19. H. Ghonem, T. Nicholas and A. Pineau, Symposium. on High Temperature Effects, (ASME, Winter annual Meeting, Atlanta, Nov. 1991). 